\title{
La involución de los formatos comerciales radiofónicos: España 10 años después
}

\author{
Irratiko merkataritza-formatuen inboluzioa: \\ Espainia, 10 urte geroago
}

\author{
Involution of the structure of radio \\ advertisements: Spain 10 years later
}

\section{Sílvia Espinosa Mirabet ${ }^{1}$ Maria Vico Blanco}

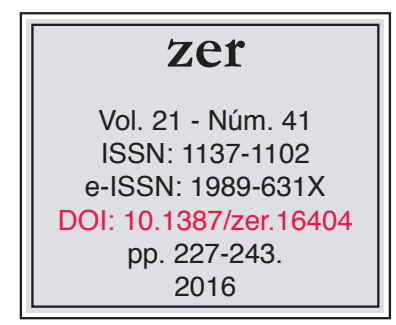

Recibido el 4 de mayo de 2016, aceptado el 3 de octubre de 2016.

\begin{abstract}
Resumen
Al cumplirse diez años de la investigación de Perona (2005) publicada en ZER en 2007 sobre la publicidad en la radio española, una investigación de la Universidad de Girona aborda el mismo objeto de estudio. El objetivo perseguido fue idéntico para poder comprobar cuál ha sido la evolución de la publicidad en la última década. El estudio, de tono cuantitativo, se ha realizado a partir de una muestra de emisoras generalistas de España. Las conclusiones no son nada halagüeñas. En 10 años los cambios más perceptibles se observan en la aparición de anunciantes nuevos procedentes de sectores productivos diferentes.
\end{abstract}

Palabras clave: Publicidad, radio, formatos, géneros, anunciantes.

\section{Laburpena}

Duela hamar urte egin zen Espainiako irratiaren publizitateari buruzko Perona ikerketa (2005), eta ZER aldizkarian argitaratu zen 2007an. Orain, Gironako unibertsitatearen ikerlan batek xede bera aztertu du. Helburua berbera izan da: publizitateak azken hamarkada honetan zer-nolako bilakaera izan duen aztertzea. Azterlan kuantitatiboa Espainiako irrati jeneralista batzuetan oinarritu da, eta ondorioak ez dira batere itxaropentsuak. Azken 10 urteotan honako hau izan da aldaketa nabarmenena: ekoizpen-sektore ezberdinetako iragarle gehiago daude.

Gako-hitzak: Publizitatea, irratia, formatuak, generoak, iragarleak.

\footnotetext{
${ }^{1}$ Universidad de Girona, silvia.espinosam@udg.edu

2 Universidad de Girona, vicomaria05@gmail.com
} 


\begin{abstract}
Ten years after the investigation of Perona (2005) published in ZER on the advertising in the Spanish radio, an investigation of the University of Girona approaches to the same object. The aim was identical to be able to verify which has been the evolution of the advertising in the last decade in the radio prime-time slot. The study, of quantitative tone, has been realized from a sample of spanish talkshow radio. The conclusions are not pleasing at all. In 10 years the most perceptible changes are observed in the transformation of the productive sectors as new advertisers.
\end{abstract}

Key words: Advertising, radio, formats, genres, evolution. 


\title{
0. Introducción
}

En 2007 Perona publicaba un artículo en ZER fruto de una investigación llevada a término dos años antes, analizando cómo era la publicidad de la radio española en prime-time. Entre sus conclusiones destacaba que la mayoría de la radio generalista apostaba por la cuña como género comercial por excelencia y que en un $70 \%$ la publicidad emitida era de carácter informativo. El mismo autor imputaba las causas de este conservadurismo al inmovilismo estructural de la radio española "con una misma oferta de programación" y un posicionamiento como medio informativoperiodístico en palabras de Balsebre (Perona y Barbeito, 2008). Diez años después parece relevante acercarse de nuevo a la misma realidad para poder evidenciar, de haberlos, los cambios más significativos de la publicidad española de esa tipología de radio, la definida por Muela (2008) como radio-información-comunicación.

Como Perona (2007) muchos han sido los autores que han calificado la publicidad radiofónica de conservadora (Muela, 2008), de servicio complementario a la publicidad televisiva (Vázquez, 2001) o de inmovilista. Emma Rodero la tildaba en 2008 de poco creativa. Balsebre et al. recomendaban a los creativos, en 2006, realizar publicidad que "se viera" con los ojos de la mente y Alonso (2004) les acusaba de no usar adecuadamente las posibilidades del lenguaje radiofónico puesto que sólo se fijaban en las palabras:

\begin{abstract}
Realmente, ¿ha evolucionado la radio publicitaria?, ¿podemos hablar de nuevos formatos publicitarios radiofónicos? Creemos que la respuesta es no; que, a diferencia de la televisión, dónde, debido a la competencia de Internet, se innova buscando nuevas fórmulas que permitan superar la saturación y llegar al público objetivo (target) de forma más efectiva, la radio continua anquilosada en los formatos de siempre y con el discurso de siempre. Incluso sus problemas son los de siempre (Barbeito y Fajula, 2005: 51).
\end{abstract}

\section{El contexto}

Para algunos académicos, el origen de esta situación está en el modelo radiofónico generalista español, centrado en la información y la opinión (Arcos y Perona, 2011) y que se viene manteniendo desde la transición. Martí vaticinó en 2004 que la transformación de la programación y en consecuencia del mercado (y por consiguiente de la publicidad) sólo se daría con la reestructuración del sector radiofónico:

Todo indica que las únicas transformaciones que puede experimentar el mercado estarán relacionadas con su redimensión, es decir, con los cambios en la estructura de algunas programaciones como consecuencia de la aplicación de políticas de eficiencia empresarial o nuevas estrategias de oferta de los propios operadores a raíz de la implantación de nuevas plataformas de difusión, esencialmente la radio digital (Martí, 2004: 32). 
Más de una década después de los augurios de Martí (2004), y a pesar de que el propósito de este articulo es el estudio de la publicidad de prime-time en las emisoras generalistas, no pueden pasar desapercibidos dos grandes cambios que marcan la tendencia actual de la radio en España.

El primero es de canal. Las empresas viven en la Red pero no de la Red. Sus contenidos son descargables y su escucha a la carta cobra mucha importancia. En este sentido estamos en la era de la segmentación de los oyentes en "función de la tecnología o de forma de consumo radiofónico: analógico-digital y/o de flujo-bajo demanda" a la que se refería Bonet en 2007. Los podcasts con o sin cuñas pre-roll, esos anuncios que suenan justo antes de empezar la emisión online, forman parte del consumo radiofónico hoy en día. En este nuevo entorno, huelga decir cómo ha variado el papel del oyente en la construcción de los contenidos gracias a la incorporación de las redes sociales en el continuum radiofónico. Estamos ante un oyente activo, generador de contenidos que en palabras de Ribes et al. (2015) se puede definir como radio prosumer todavía de madurez insuficiente.

Pero incluso en este nuevo contexto digital se advierte otra vez una disociación entre las fórmulas modernas de recepción de radio y las expresiones anquilosadas atribuibles a las estructuras publicitarias. El consumo de radio online $(15.000 .000$ usuarios diarios según Audioemotion en 2014), que no supera todavía al de ondas hertzianas (EGM 2014: 26.240.000 oyentes diarios) va a una velocidad y la publicidad radiofónica online, que es todavía muy residual, se parece demasiado a la publicidad on the air (Ribes et al., 2015). Es evidente que los cambios estructurales que vive el sector, lentos pero notorios, son todavía más pausados en cuanto a publicidad radiofónica se refieren. Una de las causas podría atribuirse al arraigado sistema de ventas de publicidad basado en equipos comerciales con marcado acento local. De hecho, el director general de Vives Radio, Ricardo Vives (2016) afirmaba recientemente en una conferencia en la Universidad de Girona que la publicidad online en la radio todavía se está desarrollando y los equipos comerciales de las emisoras que venden portal y radio no son los mismos, aunque las radios ofrecen ventajas a los pocos anunciantes que deseen ubicarse en su portal. Así y de momento la publicidad de la radio española continua generando beneficios cuando es radiada, no a través de plataformas digitales y todavía son especialmente significativos los anunciantes locales en la mayoría de cadenas estudiadas. A pesar de la fuerza local en la radio comercial es obvio que los clientes pueden escoger anunciarse en un mercado nacional o autonómico sin abandonar el soporte escogido.

En segundo lugar se han producido cambios en la estructura hegemónica de los programas generalistas de prime-time a pesar de que el magazine continua copando las mañanas de la radio en España. Estos espacios son ahora más cortos que hace diez años y en algunas emisoras son capitaneados por dos grandes estrellas, en lugar de tener a un sólo periodista como director-presentador. El histórico Hoy por Hoy de Iñaki Gabilondo en la SER es ahora de Pepa Bueno y de Gemma Nierga, que se reparten el protagonismo y el contenido en dos eslots de 4 y 2 horas respectivamente. En Onda Cero se reproduce la misma estructura. El programa matinal, Más de Uno, está presentado por Carlos Alsina y Juan Ramón Lucas. Esta división del magazine de prime-time ha contribuido a la modificación de su contenido. Si en la primera franja la información es la base sobre la que se mueven entrevistas, comentaristas 
y/o noticias, en la segunda parte se observa una aproximación al infoentretenimiento tal como lo entiende Ortells (2008). Es decir, no se trata de apostar por el sensacionalismo sino por producir contenidos aptos para todos los públicos con temas sociales cercanos al oyente, secciones donde este participa habitualmente (Ribes et al., 2015).

Bonet afirmaba en 2007 que hasta ese momento el sector radiofónico español había apostado e invertido en mejoras técnicas pero no en creatividad e innovación programática "para satisfacer nuevas demandas de audiencia que ya no escucha la radio" (Bonet,2007: 7). Habrá que comprobar si estos cambios que se nos antojan muy importantes aunque seguramente incipientes son revulsivo suficiente para que la publicidad radiofónica se transforme, teniendo muy presente la fuerte base local de las emisoras. En verdad, como apuntaban Perona y Barbeito (2008) estas innovaciones constituirían ese contexto que debería influir en el ámbito comercial. La programación generalista ya no es tan sumamente informativa aunque la publicidad continua en un plano muy racional a tenor de los datos arrojados por un análisis de contenido llevado a término en 2013 por Perelló y Muela. Los aspectos tangibles del producto y sus características eran recursos todavía muy recurrentes y abocaban a la publicidad hacia una clara infrautilización del potencial del medio. "(...) de su capacidad de sugerir cualquier objeto, persona o escenario, a través, por ejemplo, del sonido y los elementos propios del lenguaje radiofónico" (Perelló y Muela, 2013: 49).

Así pues, este artículo se plantea unos interrogantes que habrán de quedar resueltos en las conclusiones del trabajo. Para ello se parte de una pregunta de investigación general: ¿Cómo ha cambiado el uso del lenguaje radiofónico en la publicidad española de prime-time que se emite en las emisoras generalistas?. Esta cuestión se complementa con dos objetivos más: ¿Cuáles son los formatos más usados en publicidad radiada? y ¿Han variado los anunciantes en los últimos diez años? Las respuestas se obtendrán a partir del análisis de una muestra de 249 piezas publicitarias recogidas durante un mismo periodo de tiempo, del 19 de diciembre de 2014 al 28 de enero de 2015 entre las 7:00h y las 10:00h es decir durante el prime-time de la radio. Los datos han sido analizados y categorizados a partir de la observación del uso del lenguaje radiofónico empleado, de la tipología de formato más común y del género publicitario al que se adscriben los anuncios radiados en función de su contenido.

\section{Un método ad hoc para observar en detalle la publicidad radiofónica}

Las emisoras objeto de estudio han sido las estaciones generalistas que tienen cobertura por aire en todo el territorio español: Cadena SER, Onda Cero, COPE y esRadio. De aquí y mediante un sistema de grabación creado a propósito para este trabajo, se han podido obtener las unidades de análisis cuando las propias emisoras no han podido facilitar las grabaciones referentes al periodo de prime-time que es el mismo que se analiza en la investigación precedente de este trabajo. Precisamente, uno de los principales problemas para hacer una comparación válida surgió en el momento de definir el prime-time de la radio española. Si bien Perona (2007) lo situó entre las 9:00 y las 11:00 h. actualmente y según el EGM el prime-time de la radio en España se encuentra entre las 7:00 y las 10:00 h. En cualquier caso se estima que este extremo no provocará variaciones significativas en los resultados puesto que en ambos casos el período temporal analizado es el de máxima audiencia matinal. 
La muestra seleccionada ha reunido todos los anuncios emitidos, en los días y horas indicados en las emisoras objeto de estudio, independientemente de su género comercial. Concretamente la muestra se ha recogido en cuatro días laborables de diciembre de 2014 y dos de enero de 2015, coincidiendo con la campaña de Navidad puesto que es un momento álgido para la publicidad en la radio, esperando de este modo, poder obtener la máxima diversidad posible de formatos comerciales. Aunque el estudio de Perona (2007) no se realizó en ese mismo período temporal sino en meses más neutros, la prospección actual, aun con el riesgo que suponía la comparación, se llevó a cabo en ese lapso temporal con la perspectiva de observar si en un momento de máxima saturación comercial afloraban nuevas fórmulas que dieran indicios de cambios en las inserciones publicitarias. Hay que tener muy presente que incluso los antecedentes más próximos a esta investigación (Perelló y Muela, 2013) insistían en el estancamiento creativo de la publicidad radiofónica, esta vez a partir del análisis de los textos de las cuñas. "Se trate del producto que se trate, la publicidad en radio utiliza la misma estrategia discursiva, lo cual supone para el oyente una escucha repetitiva, monótona y uniforme de la que es muy fácil desconectar perceptivamente" (Perelló y Muela, 2013: 48)

Así pues, las piezas han sido recolectadas por tres vías diferentes. Por una parte y siempre que ha sido posible, se han obtenido los anuncios de la programación descargable de las webs de las cadenas. Por otro lado, algunas emisoras han cedido las grabaciones de sus programas, facilitando así la obtención de las muestras comerciales para su estudio. Finalmente y como último recurso, también se han conseguido muestras grabando de forma manual el directo de la emisora, durante las tres horas establecidas para el estudio.

En total se han obtenido 12 horas de radio, en las cuales se han podido identificar 249 piezas publicitarias que son la muestra estudiada. La publicidad se ha tratado a partir de un análisis de contenido cuantitativo.

Todos los anuncios se han analizado mediante una misma tabla de observación, elaborada $a d$ hoc y atendiendo a parámetros de estructura y de contenido. Siguiendo las indicaciones de análisis de contenido de Wimmer y Dominik (1996) se clasificaron y categorizaron las unidades observables. Sobre estructura se examinaron los formatos de cada una de las 249 inserciones y se adscribieron a la configuración clásica que realizan entre otros Barbeito y Fajula (2005) y Perona (2007): cuña, mención, ráfaga, publirreportaje, otros micro-espacios, patrocinios y autopromociones. En este trabajo también se ha prestado atención a la posible aparición del jingle, que aunque no deje de ser una variación de la cuña, su propia esencia entroncaría definitivamente con los parámetros del lenguaje radiofónico:

Un jingle es una tonada musical que se relaciona con un producto o marca (...). Esta canción puede ser cantada o solo musicada pero en ambos casos debe tener unos elementos coincidentes: debe ser fácilmente recordable por la audiencia, esto quiere decir que se debe poder tararear y además es necesario que la música se asocie rápidamente con la marca que se vende Espinosa (2012: 30). 
No se han hallado piezas de estas características.

Según Balsebre (1994) en la publicidad, el lenguaje radiofónico no debería disociarse en sus cuatro elementos básicos: voz, música, efectos y silencios, sino que a partir de su uso yuxtapuesto, debería conseguir las cuotas más altas de originalidad para poder estimular mejor la imaginación de los oyentes. Para Rodero et al. las cuatro funciones básicas del lenguaje radiofónico son elementos esenciales para la publicidad en la radio por su incidencia en el plano connotativo: "Cuatro son las funciones con las que puede emplearse el lenguaje de este medio: hacer ver, hacer sentir, informar y lograr la persuasión" (Rodero, 2004: 60).

Además se midió la duración de cada formato en antena y se vinculó cada pieza a un sector productivo en función del anunciante.

En cuanto a contenido, los anuncios se estudiaron en relación con el uso que se hacía del lenguaje radiofónico. En este sentido se han detallado aspectos vinculados a la cantidad y tipología de voces protagonistas que aparecían en cada inserción y a su género. Se ha observado el peso del silencio en los diferentes formatos. Se ha registrado si los anuncios llevaban música o no y si ésta era música original o preexistente y finalmente se ha determinado el uso de los efectos de sonido en la publicidad radiada. Después y para adscribir cada comercial a un género de contenido, se han establecido dos grandes tipologías fácilmente identificables. Los anuncios de contenido informativo (racionales) y los de contenido más creativo (emocionales), identificando en este caso si la publicidad generaba expectación en el oyente, si era un anuncio que se basaba en el humor o si utilizaba una hibridación de géneros, una mescolanza, para epatar y conseguir más significación en antena. Obviamente esta categorización podría haberse llevado a término de otro modo, pero las autoras consideraron estos aspectos como los más relevantes para identificar cambios y para poderlos contrastar con la descripción de la publicidad radiofónica que realizó Perona diez años antes.

De este modo se ha podido componer un estado del arte sobre cómo es, desde una óptica general, la estructura de la publicidad radiofónica de las radios generalistas en el prime-time. Así, se podría evidenciar la evolución de la publicidad radiofónica en España desde la publicación en la revista Zer del trabajo sobre el mismo objeto de estudio, en 2007.

\section{3. ¿Cómo es la publicidad en la radio generalista de prime-time?}

La descripción de los datos obtenidos constata que la mayoría de la publicidad en las emisoras generalistas españolas se emite en forma de cuña radiofónica y se puede observar también que el publirreportaje como género comercial en la radio no tiene ninguna significación. Ambos géneros comparten la necesaria producción y post-producción de la grabación pero a diferencia de la cuña que se caracteriza por su corta duración (no más de 20 segundos) el publirreportaje es un comercial más largo que la cuña y puede tener duraciones variables en función de las necesidades del anunciante. Además su realización es más costosa puesto que debe asimilarse al reportaje para poder gozar de esa credibilidad informativa que el cliente busca cuando encarga este tipo de formato en los anuncios de radio y esto condiciona su realización y encarece su costo. 
A continuación se reproduce una tabla (Figura 1) que resume las principales características de la publicidad analizada atendiendo a criterios de lenguaje radiofónico y de formatos comerciales. Como se puede observar además de cuñas y publirreportajes, el análisis se ha fijado también en las menciones aparecidas. "La mención es el formato ideal para muchos anunciantes, que están convencidos de que la implicación directa del locutor-estrella en la publicidad aumenta la notoriedad y la eficacia del mensaje publicitario" (Perona, 2007: 225). Además se han consignado las apariciones en prime-time de ráfagas. Anuncios comerciales muy cortos y que nada tienen que ver con las ráfagas-cortina, a las que normalmente se le atribuye la función de separación de contenidos. Se trata de versiones de cuñas en pocos segundos. Son, en palabras de Barbeito y Fajula (2005), mensajes comerciales mucho más cortos que las cuñas a las que siguen en estructura y que pueden durar entre 10 y 15 segundos. También aparecen las autopromociones de las propias cadenas para anunciar sus programas o contenidos, los patrocinios y los micro espacios comerciales. En este caso se han buscado evidencias con formatos diversos desde las clásicas entrevistas comerciales a "expertos", a los diálogos o a las formas más sofisticadas como pudiera ser un concurso de una marca.

Figura 1. Formatos dominantes y uso de lenguaje radiofónico.

\begin{tabular}{|c|c|c|c|c|c|c|c|c|c|c|}
\hline FORMATO & $\begin{array}{l}\text { Voz: } \\
1 \text { locutor }\end{array}$ & $\begin{array}{l}\text { Voz: } \\
20+ \\
\text { locutores }\end{array}$ & $\begin{array}{c}\text { Música: } \\
\text { SI }\end{array}$ & $\begin{array}{c}\text { Género: } \\
\text { Info. }\end{array}$ & $\begin{array}{l}\text { Género: } \\
\text { Expectan. }\end{array}$ & $\begin{array}{c}\text { Género: } \\
\text { Humor. }\end{array}$ & $\begin{array}{l}\text { Dura: } \\
-20 "\end{array}$ & $\begin{array}{c}\text { Dura: } \\
20 " \\
0+\end{array}$ & $\begin{array}{l}\text { Dura: } \\
+1 \min \end{array}$ & $\begin{array}{l}\text { Efectos: } \\
\text { SI }\end{array}$ \\
\hline Cuña & $55 \%$ & $45 \%$ & $90 \%$ & $54 \%$ & $12 \%$ & $1 \%$ & $11 \%$ & $88 \%$ & $1 \%$ & $20 \%$ \\
\hline Mención & $25 \%$ & $75 \%$ & $25 \%$ & $100 \%$ & $0 \%$ & $0 \%$ & $25 \%$ & $75 \%$ & $0 \%$ & $0 \%$ \\
\hline Ráfaga & $92 \%$ & $8 \%$ & $69 \%$ & $69 \%$ & $15 \%$ & $8 \%$ & $100 \%$ & $0 \%$ & $0 \%$ & $23 \%$ \\
\hline Publireport. & - & - & - & - & - & - & - & - & - & - \\
\hline Microespa. & $19 \%$ & $81 \%$ & $55 \%$ & $100 \%$ & $0 \%$ & $0 \%$ & $0 \%$ & $81 \%$ & $19 \%$ & $15 \%$ \\
\hline Autopromo. & $62 \%$ & $38 \%$ & $100 \%$ & $69 \%$ & $23 \%$ & $0 \%$ & $38 \%$ & $54 \%$ & $8 \%$ & $0 \%$ \\
\hline Patrocinio & $94 \%$ & $6 \%$ & $61 \%$ & $94 \%$ & $6 \%$ & $0 \%$ & $94 \%$ & $6 \%$ & $0 \%$ & $0 \%$ \\
\hline
\end{tabular}

Fuente: Elaboración propia.

A partir de los números alcanzados, se deduce claramente que la publicidad radiofónica actual tiene, mayoritariamente, una duración de 20 segundos y que raramente se usan formatos más largos. La duración más estándar es la que se encuentra entre los 20 y los 30 segundos, que es el tiempo empleado en los anuncios que tienen como formato la cuña ( $50 \%$ de los anuncios radiados) en su vertiente más informativa. La mención (sólo 4\% de la publicidad radiada) es un género poco común en la mañana de la radio y los sectores que optan por este formato son y por este orden: seguros y bancos, belleza y salud y los anunciantes vinculados al turismo y la cultura. Finalmente las autopromociones (7\% de las unidades analizadas) representan 
el tercer gran formato de anuncios comerciales. En las emisoras generalistas se usan las autopromociones de carácter informativo y con frecuencia se hibridan con rasgos de contenido expectante, dando así más creatividad al anuncio que no tiene otro objetivo que autopromocionar la cadena que lo emite, un programa o una sección de la misma. Los micro-espacios (6\% de los anuncios) en un $32 \%$ de las ocasiones sobrepasan el minuto y son usados principalmente en la COPE en un 13\% de su tiempo publicitario y en la cadena SER donde representan un $10 \%$ de su publicidad. Las ráfagas comerciales (6\% de la publicidad) suelen durar 10 segundos.

De la misma manera y fijando la atención en el empleo de los distintos elementos del lenguaje radiofónico, la tabla anterior (Figura 1) define las características principales de la muestra. Se advierte que la publicidad suele estar locutada principalmente por un solo locutor, cobrando fuerza la figura de ese profesional creíble con una dicción impecable que lee copys que nunca se escribe, sin equivocarse jamás (Espinosa, 2011: 114). En este sentido sí que es relevante destacar (Figura 2) que atendiendo a criterios de género, el locutor dominante continúa siendo el hombre aunque se percibe que en un $33 \%$ de la publicidad las voces protagonistas son femeninas. En este caso, las locutoras protagonizan publicidad relativa a los sectores de la alimentación (supermercados), de la moda y el textil (grandes almacenes como El Corte Inglés) y de la banca.

Figura 2. Cuñas-voces usadas en la locución. Radio generalista - Edad y género de las voces

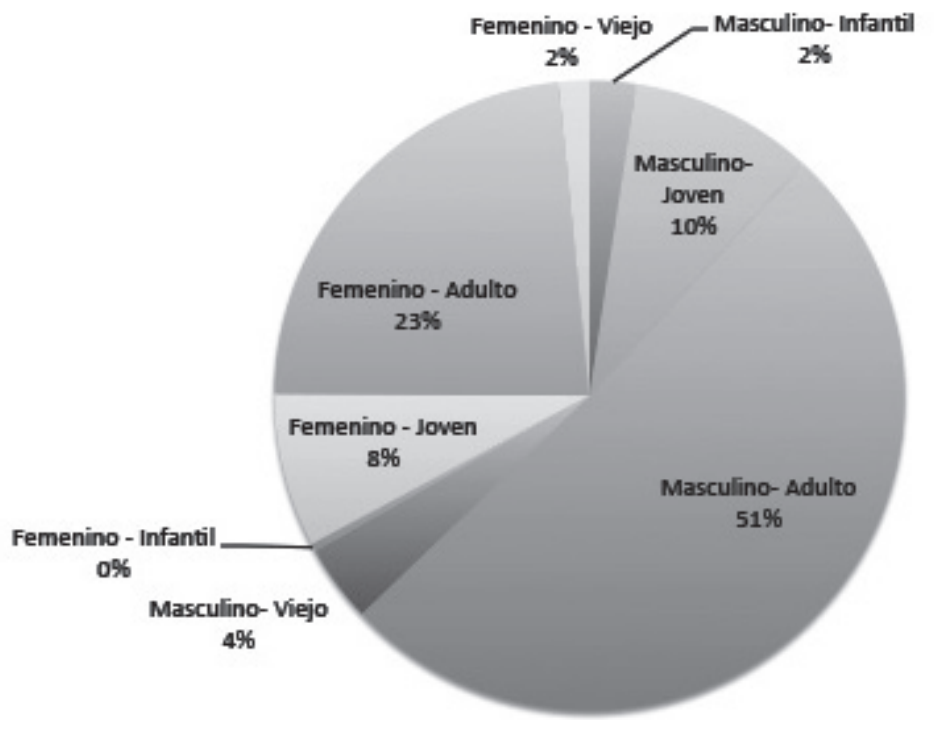

Fuente: elaboración propia.

Otro de los elementos investigados ha sido el peso de la música. En este sentido es significativa la aportación de Martín-Santana et al. (2015). Para estas autoras, si el objetivo de usar música en la publicidad radiofónica es atraer la atención del oyente y favorecer la retención de la marca, la música es una garantía de éxito, pero si lo que 
se busca es conseguir una actitud favorable hacía la marca hay que asegurarse de que exista una concordancia entre la música y el contenido del anuncio, sin congruencia es mejor no usar música. Así pues, y a pesar de esta advertencia la música forma parte de casi toda la publicidad radiofónica española, en su función ornamental. Es decir es usada para embellecer el mensaje, no para redundarlo o para connotarlo y casi siempre se percibe en un segundo plano. Se han detectado algunas tipologías de anuncio que no la emplean, este es el caso de las menciones o de los patrocinios que en los casos estudiados son a capela. La música que se utiliza para la publicidad radiofónica es casi siempre preexistente, es decir, no es original por lo que no ha sido compuesta exclusivamente para el anuncio. Parece asombroso que los publicistas no presten más atención a este elemento persuasivo cuando existen abundantes estudios (Martín-Santana et al., 2015) que afirman su importancia en la comunicación. Comunicar un producto o servicio a través de un lenguaje no verbal que acompañe a las palabras puede penetrar en el consumidor potencial de manera más subliminal y provocar un recuerdo mucho más duradero (Sánchez-Porras, 2013: 350).

Si bien la música es la pieza del lenguaje radiofónico que junto con la voz, más se aplica en publicidad, el silencio es el componente menos empleado. En todo el estudio no se ha detectado ningún anuncio que usara este recurso expresivo, dato que evidenciaría el desconocimiento que tienen los creativos sobre las reveladoras potencialidades del mismo. La ausencia de silencio en publicidad es una tendencia remarcable y recurrente en numerosos estudios previos sobre el tema (Perona, 2007; Perona y Barbeito, 2008).

Los efectos de sonido, el cuarto ingrediente del lenguaje de la radio, tampoco gozan de una presencia muy relevante en la muestra analizada. En la mayoría de anuncios, independientemente de su formato y de su contenido comercial, no se halla este recurso. Es muy bajo el porcentaje de piezas que los utiliza y cuando lo hacen, suelen desempeñar una función descriptiva-ambiental, casi nunca son empleados de forma ornamental o narrativa. Se infravalora pues la fuerza expresiva de los efectos que, per se, pueden dibujar imágenes mentales en los oyentes o despertar intensas sensaciones, propiedades muy buscadas en la creatividad publicitaria.

A continuación se reproduce una tabla resumen con el uso de la música y de los efectos sonoros en los diferentes anuncios analizados:

Figura 3. Uso de la música y los efectos en los diferentes formatos comerciales.

\begin{tabular}{|l|c|c|c|c|c|c|}
\hline & Cuña & Ráfaga & Patrocinio & Autopromo. & Microespacio & Mención \\
\hline $\begin{array}{l}\text { Contienen } \\
\text { Música }\end{array}$ & $90 \%$ & $69 \%$ & $0 \%$ & $100 \%$ & $55 \%$ & $25 \%$ \\
\hline M. Preexistente & $90 \%$ & $78 \%$ & $0 \%$ & $62 \%$ & $55 \%$ & $100 \%$ \\
\hline M. Original & $10 \%$ & $22 \%$ & $0 \%$ & $38 \%$ & $45 \%$ & $0 \%$ \\
\hline $\begin{array}{l}\text { Contienen } \\
\text { Efectos De } \\
\text { Sonido }\end{array}$ & $20 \%$ & $23 \%$ & $0 \%$ & $0 \%$ & $15 \%$ & $0 \%$ \\
\hline $\begin{array}{l}\text { Efectos F. } \\
\text { Ornamental }\end{array}$ & $24 \%$ & $33 \%$ & $0 \%$ & $0 \%$ & $33 \%$ & $0 \%$ \\
\hline $\begin{array}{l}\text { Efectos F. } \\
\text { Ambiental }\end{array}$ & $76 \%$ & $67 \%$ & $0 \%$ & $0 \%$ & $67 \%$ & $0 \%$ \\
\hline
\end{tabular}

Fuente: elaboración propia. 
Finalmente, los datos también permiten fijarse en los diferentes sectores que usan la radio generalista como soporte para su comunicación comercial. En este sentido hay que destacar que los sectores de los seguros y los bancos, son los clientes fundamentales de las emisoras en 2015 y usan para su publicidad, y por este orden, cuñas, menciones y patrocinios. Otros géneros como la ráfaga comercial son utilizados por anunciantes del sector de la alimentación. En cambio el sector del juego y del azar utiliza los micro-espacios para anunciarse en el prime-time español.

\section{Diez años después, una comparación es posible}

Respondiendo al ánimo de este artículo se ha procedido a la comparación de los resultados obtenidos hace una década (2005) con los conseguidos en esta investigación (2014-15). En la tabla siguiente (Figura 4) se muestran los elementos que han sido cruzados para poder obtener conclusiones sobre la evolución o no de la publicidad de las emisoras convencionales. Las categorías comparadas con el estudio de Juan José Perona (2007) se refieren a la distribución de la publicidad por cadenas, a los sectores de los anunciantes más recurrentes, a los géneros publicitarios radiofónicos más utilizados y finalmente, al estilo del contenido de las piezas publicitarias.

Es relevante remarcar que en diez años España tiene una cadena más de radio generalista (esRadio) con cobertura nacional, con lo cual el reparto de la publicidad en prime-time tiene más actores y está más segmentado. Aun así, teniendo en cuenta los cambios, la Cadena SER continua en la cabecera de las emisoras que más tiempo dedican a la publicidad, aunque es conveniente destacar que la reciente esRadio dedica a publicidad el mismo tiempo en minutos/programación que la Cadena SER: un $28 \%$ de los contenidos de estas cadenas nacionales son espacios comerciales.

Por otro lado, en referencia a los géneros de los anuncios también se han producido algunas variaciones. En este sentido se ha podido constatar que la entrevista como micro espacio ya no es utilizada en la radio comercial privada para la promoción radiofónica, pero en cambio hay otras fórmulas, más cortas, que cobran protagonismo, como la ráfaga y la autopromoción. No obstante, la cuña continua manteniéndose como el formato estrella de la radio española y lo hace con un porcentaje muy superior al de las otras tipologías de publicidad radiofónica. Hace 10 años el $80 \%$ de los anuncios eran cuñas y actualmente representan el $73 \%$ de las piezas radiadas.

Otro paralelismo tiene que ver con el estilo del contenido de los anuncios. A pesar de las múltiples hibridaciones en los contenidos de los anuncios estudiados, hoy en día la mayoría de piezas son informativas, así lo muestran los resultados (54\% de las cuñas son de género informativo) y así sucedía hace 10 años, cuando el $70 \%$ de los anuncios utilizaban este estilo.

Contrariamente, el único aspecto que ha cambiado en los últimos años es el del sector comercial de los anunciantes que prefieren este medio para promocionarse. Perona (2007) concluía que industrias como la del tabaco, la alimentación, la automoción, la salud o las telecomunicaciones utilizaban como soporte la publicidad radiofónica. En la actualidad, los resultados muestran un cambio de tendencia y es que las marcas que más suenan por antena provienen de sectores muy diferentes a 
los escuchados hace diez años. Ahora surcan las ondas generalistas: los seguros, los bancos y los créditos exprés, todos ellos en estricta relación con la economía recesiva que enmarca el periodo temporal analizado.

Figura 4. Comparación de la evolución

de la publicidad en la radio generalista: 2005->2014-15.

\begin{tabular}{|c|c|c|c|c|}
\hline & $\begin{array}{l}\text { Distribución de } \\
\text { la publicidad } \\
\text { por cadenas }\end{array}$ & $\begin{array}{l}\text { Sectores de los } \\
\text { anunciantes más } \\
\text { recurrentes }\end{array}$ & $\begin{array}{l}\text { Formatos } \\
\text { publicitarios } \\
\text { radiofónicos }\end{array}$ & $\begin{array}{c}\text { Estilo del } \\
\text { contenido } \\
\text { de las piezas } \\
\text { publicitarias }\end{array}$ \\
\hline 2005 & $\begin{array}{l}\text { SER }(36,1 \%) \\
\text { COPE }(33 \%) \\
\text { Punto Radio } \\
(30,9 \%)\end{array}$ & $\begin{array}{l}\text { Tabaco } \\
\text { Alimentación } \\
\text { Automoción } \\
\text { Salud } \\
\text { Telecomunicaciones }\end{array}$ & \begin{tabular}{|l|} 
Cuña $(80 \%)$ \\
Micro-espacio \\
$(10,9 \%)$ \\
Mención $(2,1 \%)$ \\
Patrocinio $(1 \%)$ \\
Entrevista $(1 \%)$ \\
\end{tabular} & $\begin{array}{l}\text { Informativo } \\
(70 \%)\end{array}$ \\
\hline $\begin{array}{c}2014 \\
-2015\end{array}$ & $\begin{array}{l}\text { SER }(28 \%) \\
\text { esRadio }(28 \%) \\
\text { Onda Cero }(27 \%) \\
\text { COPE }(17 \%)\end{array}$ & $\begin{array}{l}\text { Seguros } \\
\text { Bancos } \\
\text { Créditos exprés }\end{array}$ & \begin{tabular}{|l} 
Cuña $(73 \%)$ \\
Autopromoción $(7 \%)$ \\
Micro-espacio $(6 \%)$ \\
Ráfaga $(6 \%)$ \\
Mención $(4 \%)$ \\
Patrocinio $(4 \%)$
\end{tabular} & $\begin{array}{l}\text { Informativo } \\
(62 \%)\end{array}$ \\
\hline
\end{tabular}

Fuente: elaboración propia.

\section{Conclusiones}

La publicidad española que se emite en las emisoras generalistas en la franja horaria de prime-time tiene un perfil muy bien definido según de los resultados obtenidos. Se trata básicamente de cuñas informativas, interpretadas por un solo locutor, hombre, montadas a partir de música preexistente ( $90 \%$ de las inserciones) y que casi nunca juegan con los efectos especiales (sólo en $20 \%$ de los anuncios) y nunca con el silencio.

Esta tipología es idéntica a la que definía Perona (2007) en las conclusiones de su investigación, con lo cual y a partir de los datos sí que se puede afirmar que la publicidad en la radio convencional de España sufre un estancamiento en cuanto a la innovación en creatividad y uso del lenguaje radiofónico. También es igual el género dominante en los anuncios. Las inserciones continúan siendo mayoritariamente informativas. Los anunciantes continúan confiando en la cuña que da detalles del producto y/o de su uso y prefieren que el prescriptor sea un varón adulto. Buscan un mensaje directo, realista y asertivo que en demasiadas ocasiones emplea la pregunta retórica como arranque comercial. La repetitiva estructura de los copys, como se ha explicado, y la baja intensidad creativa en los montajes, además del uso de las mismas voces de siempre y de la música preexistente convierten a la publicidad de la radio en esa tonada que siempre suena igual. Hay que tener en cuenta además que la duración de la mayoría de las cuñas también es parecida, con lo cual se genera un ritmo excesivamente previsible. En un entorno así es muy complicado destacar, aunque parece que esta no es una preocupación de los anunciantes puesto que llevan más de una década pagando por lo mismo. 
En la vieja estructura que pervive y lejos de la cuña, se empiezan a percibir algunos cambios. A diferencia de lo que ocurría en la década anterior, ahora la publicidad apuesta claramente por formatos mucho más cortos en duración.

Es fácil distinguir como ahora los anuncios más breves han cobrado protagonismo en las ondas, en detrimento de las fórmulas más extensas y más tradicionales. Así se observa, por ejemplo, que los micro-espacios, ya en antena en los años 30 del siglo pasado, se usan menos actualmente que en 2005. Lo mismo sucede con los publireportajes. En ambos casos y dejando al margen la creatividad que se les presupone por el mero hecho de ser anuncios publicitarios, la realización de estos espacios ha caído en franca decadencia. Su producción es costosa por laboriosa técnica, semántica y estéticamente por lo que su costo económico de entrada es más alto que el que se requiere para la producción de otra tipología de anuncio más reducido en minutos, como puede ser la cuña o los nuevos formatos que han surgido en el actual entorno económico recesivo, como es el caso de la ráfaga comercial.

Por este mismo motivo se puede explicar el claro auge percibido en el uso de los patrocinios, que ahora se radian un 3\% más que hace diez años o de las menciones que doblan su presencia en la antena generalista. Con la mención hay que hacer una reflexión más profunda. Si bien es cierto que por su baja complejidad de producción, sólo hace falta un buen copy y contar con un locutor profesional que sepa interpretarlo debidamente, es un género fácilmente radiable, es también una fórmula comercial cara cuando su lectura recae en un locutor del star sytem radiofónico. A pesar de eso no tiene una estructura complicada y al igual que sucede con el patrocinio, son formatos elásticos, es decir pueden ser muy breves, una simple oración, o pueden ser más prolongados si el anunciante lo necesita. Son micro-géneros versátiles.

En este entorno protagonizado por formatos publicitarios cortos, hay que situar el nacimiento de la ráfaga con finalidades comerciales. Esta tipología sería la versión radiada de los teasers comerciales televisivos. Son inserciones cortas que normalmente aparecen después de la puesta en antena de la cuña, su antecedente natural y más largo, con la que combinan rotación en antena. En esta investigación se han detectado ráfagas comerciales inferiores a 10 segundos y a pesar de que innovan en formato, se estancan en el uso del lenguaje radiofónico. La mayoría de las unidades estudiadas (75\% de las ráfagas) son informativas es decir están a la misma altura creativa que las cuñas, las verdaderas estrellas de la publicidad radiada.

Las ráfagas comerciales se realizan a partir de una voz, normalmente masculina, que lleva una música preexistente en segundo plano y juegan con efectos de sonido en su función ambiental, para contextualizar el entorno en el que trascurre el anuncio. De todas las inserciones analizadas son las ráfagas las que más veces inciden en el género del humor (6\% de los anuncios en este formato) y en la publicidad expectante (16\% de las ráfagas) muy por encima del resto de los anuncios contemplados. Se percibe pues que este nuevo formato se acerca, más que el resto de fórmulas, al terreno de la publicidad creativa, aunque de forma muy residual, puesto que la mayoría de ráfagas, como se ha mencionado, son absolutamente informativas.

De hecho, el conjunto de anuncios del prime-time son racionales pero lo son en un $7 \%$ menos que hace diez años y su contenido informativo ha descendido 16 puntos respecto al estudio de Perona (2007). Este extremo indica que ahora las cuñas se usan como soporte menos veces y que se radian muchas más cuñas no informativas 
que en 2005; por lo que se puede deducir que la creatividad en la radio se está abriendo paso explorando nuevos formatos desde la hibridación de géneros, por ejemplo.

Así los datos de la investigación empujan a afirmar que la situación económica ha tenido mucho que ver con los pequeños cambios detectados en la publicidad de las emisoras generalistas. La ha abocado a usar formatos más sencillos en su producción, más cortos en tiempo de antena y por lo tanto más baratos. Este giro hacía una publicidad de formato low cost ha tenido también repercusión en la creatividad de los anuncios, a tenor del uso de los elementos propios del lenguaje radiofónico. El efecto producido está en la misma tesitura low cost. Se reduce la presencia de los elementos expresivos y se apuesta por una publicidad que juega básicamente con la música y la voz.

En el caso de las voces, continúa predominando la publicidad locutada por varones en detrimento del protagonismo de las voces femeninas. A pesar de ello, cabe destacar que en estos diez años de evolución se registra un aumento de la presencia de la mujer en la publicidad radiada. Las voces femeninas son protagonistas de los anuncios en un $33 \%$ de las piezas de prime-time y lo que es más relevante es que las locutoras son voces prescriptoras de sectores, antes prohibidos, como la banca que tradicionalmente era locutada por varones. A pesar de esta significativa variación, imputable a un perceptible cambio social en España, la independencia económica de las mujeres significa su necesaria gestión financiera y la publicidad lo refleja, es evidente que en la radio continua imperando un modelo publicitario con predominio de voces masculinas adultas.

En el plano musical, se acentúa la falta de creatividad en la publicidad al constatar el uso de música preexistente por encima de la música original, más cara, cosa que explicaría la falta del jingle como formato comercial. En los datos obtenidos de la muestra analizada no se ha detectado ningún anuncio con esa rica e histórica fórmula cuando por su propia esencia es una tipología altamente adecuada para la radio. En cambio la publicidad se resuelve mayoritariamente con música de librería, más barata que encargar una pieza inédita a un compositor. Tampoco se usa el silencio, como se ha relatado anteriormente, claro reflejo del poco avance creativo que tiene la radio. Los efectos sonoros se detectan solamente en la mitad de los formatos estudiados. Son mayoritariamente usados en un $20 \%$ de las cuñas, ráfagas (23\%) o micro-espacios (15\% incorporan efectos). Su uso se adscribe a la función ambiental, es decir cuando se describe un lugar, los efectos refuerzan esa imagen de playa, de verano o de felicidad. De esta manera se intensifica la sensación de credibilidad del mensaje (Perona y Barbeito, 2008), extremo éste absolutamente concordante con el género publicitario predominante en el análisis, la publicidad informativa o racional.

A pesar de los pequeños atisbos de cambio, se puede constatar la no evolución en el plano creativo quizás porqué algunas de la rutinas de producción de la publicidad en la radio no han variado y posiblemente se han visto mermadas con los recortes restrictivos de plantillas que han sufrido muchas emisoras. Si como dice Vives (2016) en España un segmento de la publicidad radiofónica se explota a partir de las emisoras locales, se puede afirmar que su producción y realización también se ejecuta en un ámbito muy local y hay pocas estaciones locales con estructura suficiente como para disponer de un Departamento de márquetin o creatividad. En 2015, las grandes agencias de publicidad continúan tratando a la radio como a un medio 
subsidiario de la televisión (Balsebre et al., 2006). Esto explicaría como no es difícil detectar publicidad radiofónica con las mismas características que la que se emitió hace 10 años. Se repiten los patrones (y las voces) y se detectan todavía anuncios que son versiones televisivas de las marcas. Se apuesta por una fórmula barata en su concepción para poder resistir la competencia y parece que funciona.

La diferencia más notable se identifica en los anunciantes. Hay nuevos sectores productivos que confían en la radio y que tienen una presencia en antena muy superior a los clientes de siempre. Esta variación es fruto del contexto económico y social español en el momento de efectuar la recogida actual de los datos. La publicidad que más se promueve en 2014-2015 responde a ese sector de clientes (a veces nuevo) que han encontrado en la crisis económica una nueva vía de negocio. Así, bancos, créditos exprés o empresas aseguradoras usan ahora este medio como plataforma de comunicación con sus clientes. Son ámbitos que vienen a cubrir las necesidades económicas que sufren los oyentes/clientes. En 2005, la situación económica en este país era radicalmente diferente y la radio como reflejo que es de la sociedad, recibía anuncios de sectores muy alejados de las restricciones que impone una recesión. Entonces los anunciantes del prime-time radiofónico generalista eran sectores vinculados al gasto y al consumo masivo: los automóviles, las telecomunicaciones, la alimentación o el tabaco (La ley antitabaco todavía no se había aprobado).

En relación a la segmentación del mercado cabe destacar que las emisoras generalistas de ámbito estatal son cuatro en lugar de tres, como sucedía en 2005, cosa que explicaría el leve descenso en cuanto a la distribución de la publicidad por cadenas en su franja de máxima audiencia.

En 2015, a pesar de que el sector radiofónico español movía alrededor de 286,2 millones de euros anuales, un 8,4\% más que el año anterior según datos de Arce Media y i2 $\mathrm{P}^{3}$, la publicidad radiofónica continuaba siendo un separador de contenidos de la antena. Los datos evidencian que el sector se está recuperando de la recesión, que las parrillas programáticas prueban nuevos encajes, que el consumo de la radio está cambiando con las posibilidades de Internet pero demuestran también que la creatividad continúa estancada y que las innovaciones más perceptibles se reflejan en la aparición de formatos comerciales más cortos y por consiguiente más baratos.

Quizás el futuro de la publicidad en la radio no pase por implementar un mayor uso creativo del lenguaje radiofónico sino por desarrollar experiencias de branded content. Es decir, crear valor para compartir con los clientes mediante información, entretenimiento o experiencias (Del Pino-Romero y Castelló-Martínez, 2015) integrados en los contenidos de la programación generalista. Este es el objetivo de una nueva investigación.

Datos disponiblesn en: http://prnoticias.com/radio/20145642-radio-inversion-publicidad-infoadex-i2p. 


\section{Referencias bibliográficas}

Aimc. Asociación para la Investigación de Medios de Comunicación (2015). Resumen general de resultados EGM: Abril 2014 a Marzo 2015. Recuperado de http:// www.aimc.es/-Datos-EGM-Resumen-General-.html

ARCOS, N., y PERONA, J. J. (2011). Modalidades, usos y presencia de la ficción como recurso creativo en la publicidad radiofónica. Anàlisi, $\mathrm{n}^{\circ} 43$. Recuperado de https://ddd.uab.cat/pub/analisi/02112175n43/02112175n43p1.pdf

ALONSO, C. M. (2004). El canto de las sirenas: comunicación y persuasión en la publicidad radiofónica. Salamanca: Universidad Pontificia.

BALSEBRE, A. (1994). El lenguaje radiofónico. Madrid: Ediciones Cátedra.

BALSEBRE, A., RICARTE, J. Ma , PERONA, J. J., ROCA, D., Barbeito, M. L, y FAJULA, A.(2006). Los mitos de la publicidad radiofónica. Estrategias de la comunicación publicitaria en la radio española. Madrid: Ediciones Cátedra.

BARBEITO, M. L, y FAJULA, A. (2005). La ràdio publicitària: el pes de l'immobilisme. Quaderns del CAC, 22. Recuperado de https://www.cac.cat/pfw_files/ $\mathrm{cma} /$ recerca/quaderns_cac/Q22barbeitofajula_ES.pdf

BONET, M. (2007) Nuevos caminos para la radio. Un proceso productivo digital para un negocio analógico. Telos, 73. Recuperado de https://telos.fundaciontelefonica.com/telos/perspectivagrabar.asp@idarticulo=1\&rev=73.htm

DEL PINO-ROMERO, C., y CASTELLÓ-MARTÍNEZ, A. (2015). La comunicación publicitaria se pone de moda: branded content y fashion films. Revista Mediterránea de Comunicación: Mediterranean Journal of Communication, 6(1). Recuperado de https://dialnet.unirioja.es/servlet/articulo?codigo=4976215

ESPINOSA, S. (2011). Las primeras locutoras y la historia de la radio. El caso de Cataluña, 1924-1939. ZER, Revista de estudios de comunicación, $\mathrm{n}^{\circ}$ 16. Recuperado de http://www.ehu.eus/zer/es/hemeroteca/articulo/Las-primeras-locutoras-y-la-historia-de-la-radio-El-caso-de-Cataluna-1924-1939-/468

ESPINOSA, S. (2012). Análisi de un jingle icónico: ¿Por qué cuesta tanto crear otro Negrito del Cola-Cao? Icono 14. Revista de comunicación y tecnologías emergentes, 10. Recuperado de http://icono14.es/actas/index.php?conference=cpr\&schedConf $=2 \mathrm{cpr} \&$ page $=$ paper\&op $=$ viewFile\&path $\% 5 \mathrm{~B} \% 5 \mathrm{D}=727 \&$ path $\% 5 \mathrm{~B} \% 5 \mathrm{D}=308$

MARTÍ, J. M. (2004). L'oferta radiofònica a Catalunya, entre la maduresa i la crisi. Quaderns del CAC, 18. Recuperado de https://www.cac.cat/pfw_files/cma/recerca/quaderns_cac/Q18jmmarti.pdf

MARTÍN-SANTANA, J., REINARES-LARA, E., y MUELA-MOLINA, C. (2015). Music in radio advertising: effects on radio spokenperson credibility and advertising effectiveness. Psychoogy of Music, 43(6). Recuperado de http://pom.sagepub.com/content/early/2015/02/18/0305735614567701

MORENO, E. (2005). Las “radios” y los modelos de programación radiofónica. Comunicación y Sociedad, 1(18). Recuperado de http://dialnet.unirioja.es/servlet/ articulo?codigo $=1234900$ 
MUELA, C. (2008). La representación de la realidad en la cuña publicitaria. Comunicación y Sociedad, 2(21). Recuperado de http://www.unav.es/fcom/communication-society/es/articulo.php?art_id=15

ORTELLS, S. (2008). La Redefinición de los géneros periodísticos, el infoentretenimiento como punto de partida del cambio. Fòrum de recerca, 13. Recuperado de https://dialnet.unirioja.es/servlet/articulo?codigo=4714644

PERELLÓ-OLIVER, S. y MUELA MOLINA, C. (2013) Análisis de contenido de la publicidad radiofónica en España. Methaodos. Revista de ciencias sociales, 1. Recuperado de http://www.methaodos.org/revista-methaodos/index.php/ methaodos/article/view/24/16

PERONA, J. J. (2007). Formatos y estilos publicitarios en el prime-time radiofónico español: infrautilización y sequía de ideas. ZER, Revista de estudios de comunicación, 12. Recuperado de http://www.ehu.eus/zer/en/periodicals/article/ advertising-formats-and-styles-onspanish-prime-time-radiounderuse-and-shortage-of-ideas $/ 340$

PERONA, J. J. y BARBEITO M. L. (2008). El lenguaje radiofónico en la publicidad del prime-time generalista. Los anuncios en la "radio de las estrellas". Telos, 77. Recuperado de https://telos.fundaciontelefonica.com/telos/articulodocumento. asp@idarticulo=1\&rev=77.htm

RIBES, X., MONCLÚS, B., y GUTIÉRREZ, M. (2015). Del oyente al radio prosumer: gestión de la participación de la audiencia en la radio del siglo XXI. Trípodos, 36. Recuperado de http://www.tripodos.com/index.php/ Facultat_Comunicacio_Blanquerna/article/view/242

RODERO, E. (2008). Publicidad en radio: Publicidad, sí, pero no radiofónica. Área abierta, 20. Recuperado de http://revistas.ucm.es/index.php/ARAB/article/view/ ARAB0808230001E/4139

SÁNCHEZ-PORRAS, M. J. (2013). La persuasión de la música en la publicidad. El ejemplo Coca-Cola. Historia y Comunicación Social Vol. 18. Recuperado de http://revistas.ucm.es/index.php/HICS/article/view/44333/41891

VÁZQUEZ, M. (2001). La infravaloración publicitaria del medio radio. Revista latina de comunicación, 37. Recuperado de http://www.revistalatinacs.org/2001/ zenlatina37/139gestal.htm

VIVES, R. (2016). Conferencia sobre la gestión publicitaria de la radio en España. UdG. Datos obtenidos del portal de su empresa Vives Radio. Recuperado de http://www.vivesradio.com/RadioEspana/PublicidadEspana.html

WIMMER, R. y DOMINIK, J. (1996). La investigación científica de los medios de comunicación. Una introducción a sus métodos. Barcelona: Bosch. 